\title{
JRC2006-94036
}

\section{LATERAL STABILITY PERFORMANCE IN UNI-DIRECTIONAL ROLLINGSTOCK}

\author{
Scott A. Simson \\ Centre for Railway Engineering \\ Faculty of Engineering Central Queensland University \\ Rockhampton, Queensland 4702 \\ Australia \\ E-mail s.simson@cqu.edu.au
}

\begin{abstract}
The worn wheel profiles generated by uni-directional wagon travel produce different profile shapes on the leading and trailing wheelsets of each bogie. In the case examined both leading and trailing wheels wear to profiles having greater effective wheel conicity. The leading worn wheels exhibit flange and tread wear and the worn profile has highly nonlinear conicity having little vertical displacement over the middle range of lateral displacement. A large vertical displacement is still achieved by the worn leading wheel profile in the last section of the flangeway clearance. The worn trailing wheels have only tread wear with near linear effective conicity across the flangeway.
\end{abstract}

The hunting instability performances of the vehicle with the uni-directional wheel wear profiles is shown to have a higher critical speed than new wheel profiles due to the mismatch of the leading and trailing wheel profiles. The leading wheels of the bogie hunt with a wavelength of 26-30 m whilst the trailing wheels hunt at a wavelength of 12-16 m. Because of the differing frequency responses in the front and rear wheelsets of each bogie, lateral instability is damped for the worn wheel profiles. The worn profiles' curving performance is also improved due to increases in the total profile conicity.

Individually the leading wheel worn profile with its nonlinear conicity across the flangeway has lower critical speed than a new wheel profile, the non-linear shape leading to chaotic lateral instability. The trailing wheel profile with its highly linear conicity across the middle of the flangeway has classic sinusoidal hunting at a much reduced critical speed and much reduced wavelength. The worn wheel profiles by themselves for both leading wheel and trailing wheel are found to have critical speeds $80 \%$ of the new wheel profile critical speed. In combination as found in a wagon operating in one direction, the leading and trailing wheel profiles produce a critical hunting speed $125 \%$ of the new wheel profiles' critical hunting speed.

\section{INTRODUCTION}

Rail CRC Australia has been investigating the influence of bogie rotation friction on wheel wear. Part of the research was a simulation case study of Queensland Rail's coal freight operations in Central Queensland. The rollingstock investigated is 106 ton $1065 \mathrm{~mm}$ gauge bottom dump VSA Class (Figure 1) coal wagon. The wagon has three piece ride control bogies which travel exclusively in one direction due to the door opening and closing mechanisms. The nominal wheel diameter on the tap line is $915 \mathrm{~mm}$.

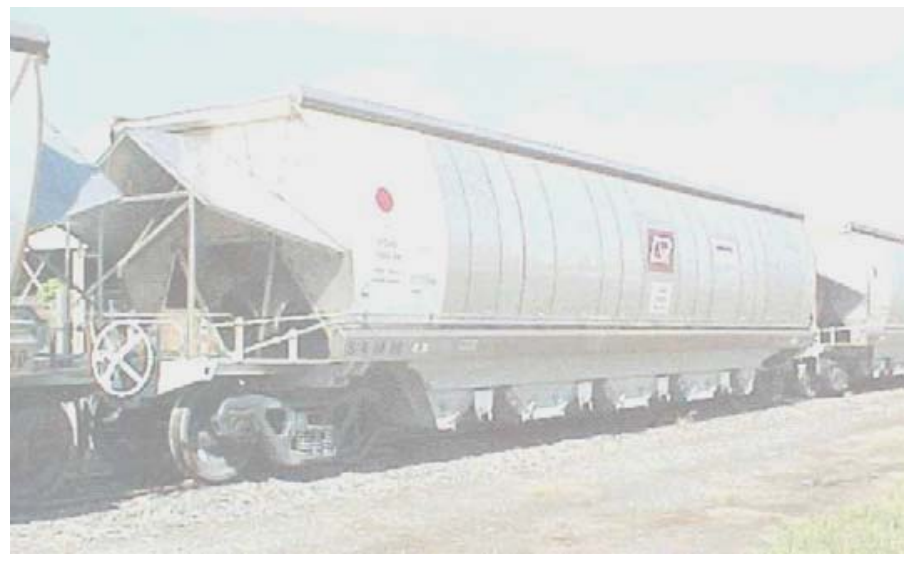

Figure 1 VSA Wagon

\section{VEHICLE DYNAMICS SIMULATION}

Simulation has been done with a 62 degree of freedom vehicle model using the VAMPIRE® vehicle simulation software. The model includes Constant Contact Side Bearers (CCSB) with a preload on a wear pad and a normal travel 6.5 
$\mathrm{mm}$ gap to rollers. High friction coefficient of 0.5 is used in modeling of the CCSB. The CCSB preload is $81.2 \mathrm{KN}$ of the wagon body's static empty load of $115.5 \mathrm{KN}$. The simulation calculations in VAMPIRE have been set at $25 \mathrm{kHz}$ with the output data being analysed using just $200 \mathrm{~Hz}$. All the simulations are run with a rail friction coefficient of 0.45 at the top of rail and at the gauge face.

\subsection{Bogie Connection Models}

The centre bowl connection model has been developed from a model used for centre bowl impacts, [1] and is a more detailed full vehicle model than used by $\mathrm{Wu}$ [2] or Katta and Thomas [3].

Six non-linear springs and matching linked friction element pairs are used for the plate of the centre bowl. Eight non-linear springs are used for the centre bowl rim with matching plate friction elements. Each rim spring element has $7.5 \mathrm{~mm}$ clearance. Each CCSB has a non-linear spring and plate friction pair for the wear plate and a non-linear spring and line friction element for the roller. The use of plate friction modeling is important to rotational friction modeling as it accounts for longitudinal and lateral movement effects on the rotational resistance of the centre bearing [1]. The linked six vertical springs and six plate friction elements of the centre bowl are important to the calculation of rim contact forces [4].

The bearing adaptor is also modeled with vertical nonlinear springs and a pair of plate friction elements at nominal separation to give rotational friction at the adaptors. There has been no accurate calibration of the friction coefficients used at the side bearers or the bearing adaptors; in both cases the friction coefficients are thought to be variable. For the simulations conducted, a 0.5 friction coefficient was used at the side bearers and bearing adaptor friction was reduced to 0.182 to achieve a reasonable critical hunting speed on the new wheel profile of $27 \mathrm{~m} / \mathrm{s}$. These model arrangements of friction coefficient are referred to elsewhere in the paper as the default case.

\subsection{Wheel/Rail Profiles}

The VSA operation is in one direction only due to the use of the KWIK drop doors system on these wagons. New and worn wheel profiles have been used in the analysis with worn wheel profile data for each wheelset. The leading and trailing wheels of each bogie exhibit different wheel wear patterns. QR supplied worn profiles for several VSA wagons. The most heavily worn wagon was chosen for use in the case study. Also supplied were rail profiles for tangent rail in the Goonyella system. Examples of the wheel/rail contact profiles are shown for tangent rail in Figure 2, Figure 3 and Figure 4. QR wheel and rail profiles are not shown in this paper. The $\mathrm{QR}$ worn wheel profiles were matched to the new wheel profile in unworn areas of the flange tip and the outer edge of the tread. The nominal diameter used in Figure 2 to Figure 4 is $910 \mathrm{~mm}$.

Noticeable in the new wheel profile, (Figure 2) is a nonlinear distortion at $5 \mathrm{~mm}$ either side of the centre line. This distortion of the otherwise smooth contact profile dramatically changes the effective conicity of the wheel for larger deviations from the centre line. The falling tails of either wheel indicates greater steering could be achieved with widening the rail gauge with the new wheel profile.

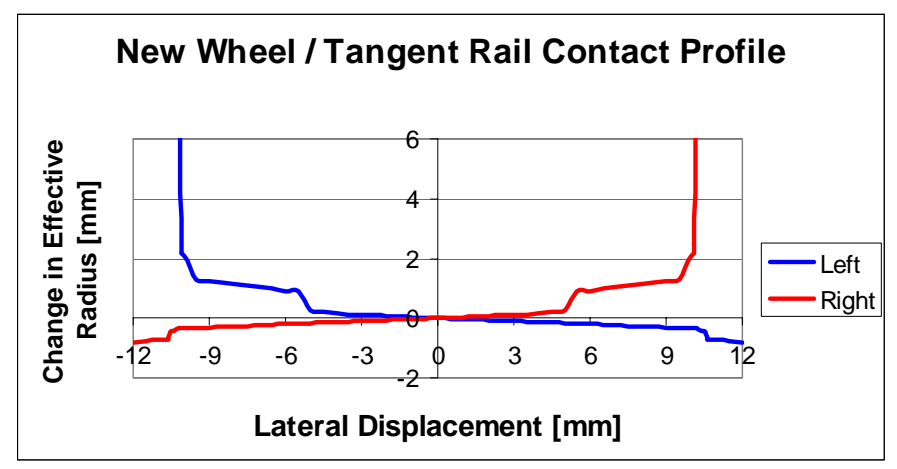

Figure 2 New Wheel, Tangent Rail Contact Profile

The worn wheel profiles of the leading bogie (Figure 3 and Figure 4) indicate that the case study wagon has tracking problems, the neutral tracking position being left $8 \mathrm{~mm}$ for the leading wheelset Figure 3 and left $1 \mathrm{~mm}$ for the trailing wheelset, Figure 4. The trailing bogies' wheels likewise have 8 $\mathrm{mm}$ left neutral position of leading wheel and $1 \mathrm{~mm}$ right on the trailing wheelset.

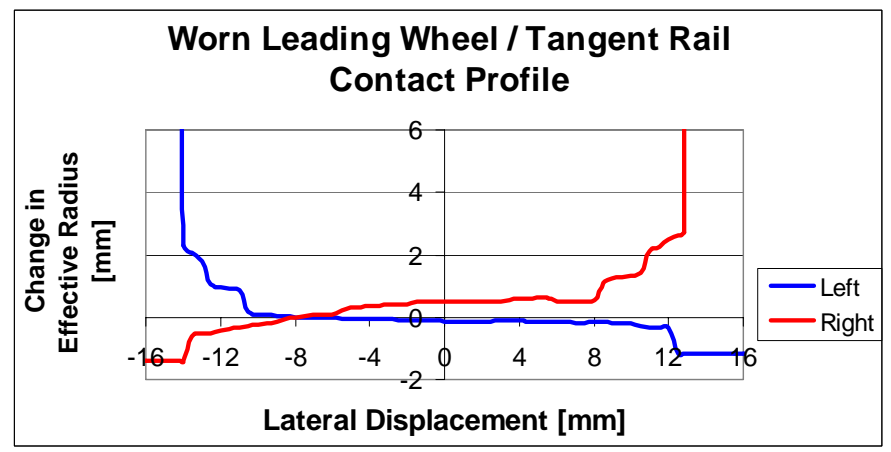

Figure 3 Wheelset 1 worn, Tangent rail contact profile

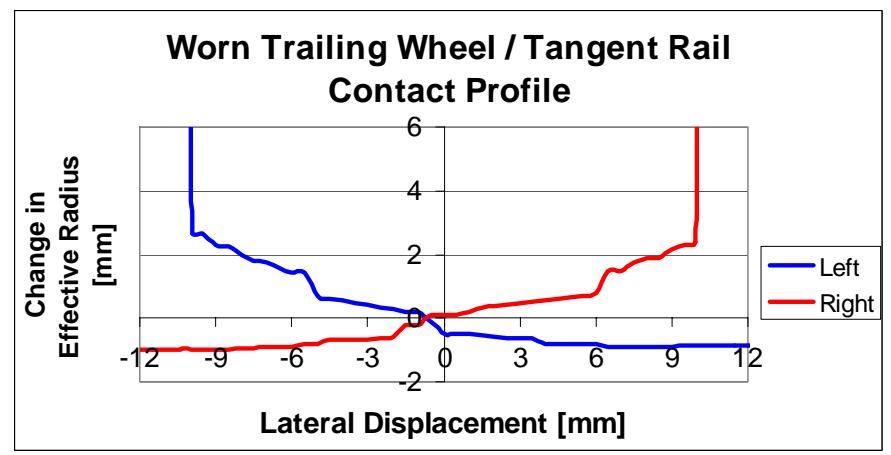

Figure 4 Wheelset 2 worn, Tangent rail contact profile

The leading wheel profile (Figure 3) has little vertical displacement between $-10 \mathrm{~mm}$ and $8 \mathrm{~mm}$ lateral displacement. In the leading wheel the left hand flange is more heavily worn than the right flange. However, a large vertical displacement is still achieved by the worn leading wheel in the last $4 \mathrm{~mm}$ of 
travel to flanging. The falling tails of the leading wheel profiles means gauge widening is likely to improve tight curve steering.

For the trailing wheel profile (Figure 4) there is a steady change in vertical displacements and a high effective conicity. A flat tailing end to the contact profile of the trailing wheel profile means gauge widening is unlikely to improve tight curve steering. The trailing wheel behaviour will be comparatively linear in nature due to the near linear change of wheelset conicity.

\subsection{Klingel Effect Analysis}

From the wheel conicity we can establish a kinematic estimate of the likely oscillation wavelength using Klingel's formula [5] (Equation 1). Klinngel's formular assumes linear conicity with no flange contact and free movement of the wheelset. We can expect a longer wavelength for wagon oscillations due to the movement restraints imposed by the bogie. In the analysis I have also included the conicity from the central or neutral zone of the wheel rail contact profile which are much lower then total effective conicity for some of the wheel profiles.

$$
\begin{aligned}
& \Lambda=2 \pi\left(r_{o} l / \lambda\right)^{1 / 2} \\
& \Lambda=\text { Wavelength of oscillation (Table } 1) \\
& r_{o}=\text { Nominal wheel radius }=0.455 \mathrm{~m} \\
& l=\text { half gauge width }=0.534 \mathrm{~m} \\
& \lambda=\text { Angle of conicity (Table } 1)
\end{aligned}
$$

Table 1 Wheel Profile Conicity and Klingel Wavelengths

\begin{tabular}{|l|c|c|c|c|c|}
\hline & New Wheel & Wheelset 1 & Wheelset 2 & Wheelset 3 & Wheelset 4 \\
\hline $\begin{array}{l}\text { Total Conicity } \\
\text { Neutral Zone } \\
\text { Conicity }\end{array}$ & 0.086 & 0.143 & 0.174 & 0.137 & 0.183 \\
\hline $\begin{array}{l}\text { Klingel Wave } \\
\text { Length Total [m] }\end{array}$ & 10.6 & 0.022 & 0.137 & 0.023 & 0.193 \\
\hline $\begin{array}{l}\text { Klingel, Neutral } \\
\text { Zone [m] }\end{array}$ & 15.2 & 21.0 & 8.4 & 20.4 & 7.1 \\
\hline
\end{tabular}

\section{RESULTS}

Hunting performance was simulated using $400 \mathrm{~m}$ tangent track section with track misalignment located between $80-92 \mathrm{~m}$ of $1.5 \mathrm{~mm}$ lateral misalignment, $12 \mathrm{~m}$ wavelength, of the track centre line to cause a lateral excitation of the wagon. The track is otherwise straight or perfect with no vertical or cross level misalignment of any kind. Unstable hunting behavior was considered to occur should the wagon exhibit wheelset lateral instability during simulation from $200-400 \mathrm{~m}$ along the track section. The specific test used assessed the lateral displacement maximum and minimum for $200-400 \mathrm{~m}$ along the simulation $120 \mathrm{~m}$ past the beginning of the track misalignment on the lead wheelset of each bogie. If the difference in lateral displacement was greater than $12 \mathrm{~mm}$ then hunting was considered as occurring. Most stable behavior responses are damped out in 50 $\mathrm{m}$ of the track defect (Figure 5). Hunting behaviors (Figure 6) meeting the test typically exhibited oscillating flange contact on one if not two wheelsets in front bogie only.

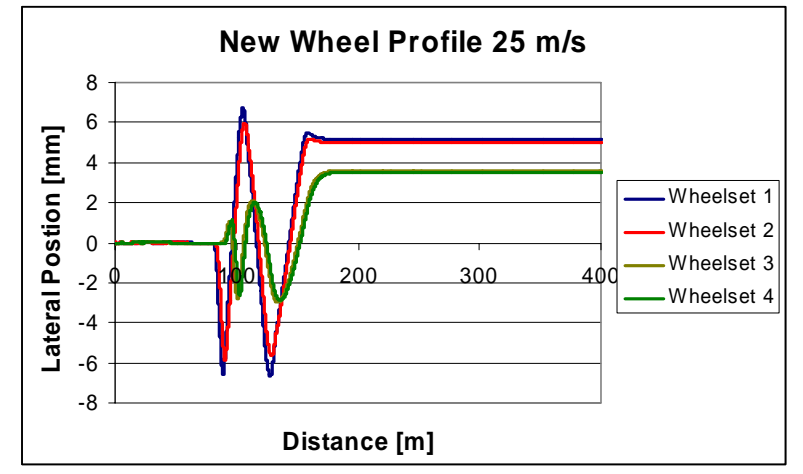

Figure 5 Example of stable behaviour in hunting simulations

The steady state offset taken up by the wheels after the track misalignment seen in Figure 5 is normal for such a fully non linear model for a three piece bogie simulated with perfect smooth track. The steering forces generated by the wheelset offset are opposed by friction at the bearing adaptors, secondary suspension friction wedges, the centre bearing and lateral creep forces at the wheel rail interface. The four wheelsets retain small angles of attack to counter the steering of the lateral offset. In real operation, small perturbations in the track would help to free movement at the bearing adaptors and the secondary suspension friction wedges reducing the size of stable offsets.

\subsection{New Wheel Profile Performance}

Using the new wheel profile a track defect is used to excite lateral instability. A $1.5 \mathrm{~mm}$ track lateral oscillation is used and disturbs the first bogie $6.5 \mathrm{~mm}$ off centre. The trailing bogie is only disturbed $2.5 \mathrm{~mm}$ from the track centre line (Figure 5). The leading bogies tracking position thus moves beyond the non-linear distortion in the contact profile seen in Figure 2 at $5 \mathrm{~mm}$ either side of centre. The lateral track defect chosen hence excites a single bogie hunting mode as shown in Figure 6. The trailing bogie, being excited only $2.5 \mathrm{~mm}$, is not made unstable.

With hunting taking place on the lead bogie the trailing bogie is forced into following the lead bogie but never actually becomes unstable in the simulations that have been run, (Figure 6). This might be altered with a multiple wagon simulation with coupler connection forces. In a train situation, coupler connections alter the hunting behavior and encourage in phase hunting of both bogies.

For the single wagon simulation to encourage in phase hunting, the wagon bogie centre distance of $11.77 \mathrm{~m}$ would need to be a good match to the hunting wavelengths or be a multiple of the hunting wavelength. In Figure 6 we can see that as the train speed increases the hunting wavelength is unchanged at approximately $15 \mathrm{~m}$ which is much higher than Klingel wavelength of the total conicity but a close match to the neutral zone wavelength of $15.2 \mathrm{~m}$. The poor match of hunting wavelength and bogie centre length damps out in phase hunting. The amplitude of hunting motion increases with speed in Figure 6 this is most evident for the second wheelset. The second wheelset oscillation amplitude increasing from 8 to 11 $\mathrm{mm}$ with speed increases from $35 \mathrm{~m} / \mathrm{s}, 45 \mathrm{~m} / \mathrm{s}$. 

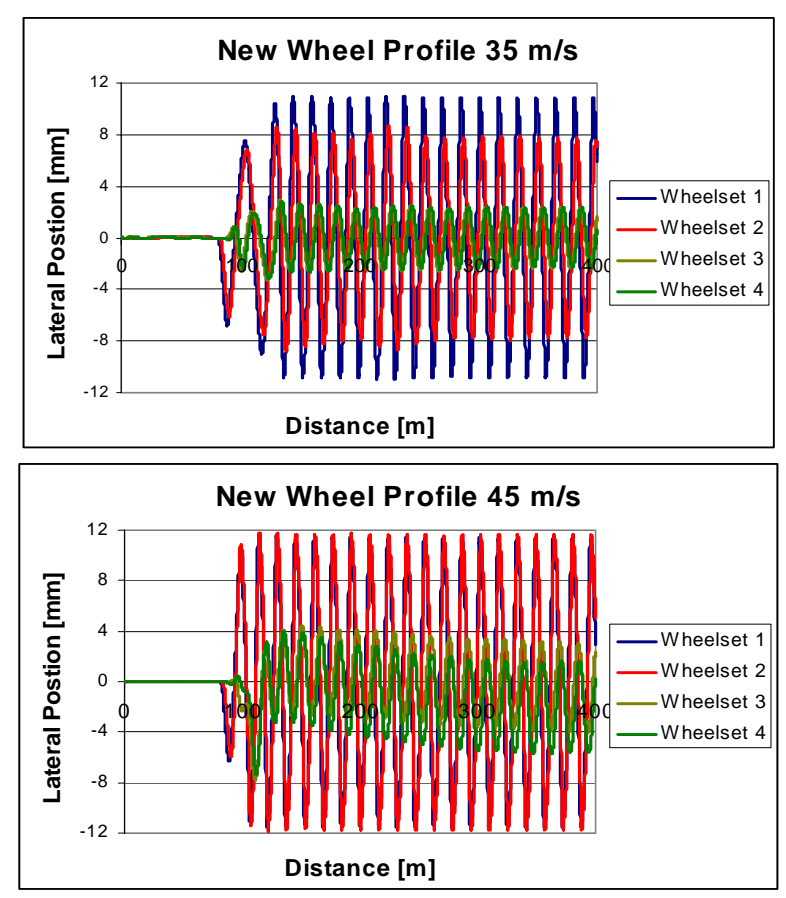

Figure 6 Hunting behaviour of New Wheel Profile

\section{Non-linear Anomaly}

Simulations were done to see what difference a smaller track defect would have on the hunting speed should the wagons' lateral shift be kept to the low conicity region of the new wheel profile. Figure 7 shows the breakout of critical hunting using a small track defect of a $1 \mathrm{~mm}$ lateral oscillation. The results show the smaller track defect gives stable performance to a much higher speed of $42 \mathrm{~m} / \mathrm{s}$ compared to 27 $\mathrm{m} / \mathrm{s}$ that the model's pedestal friction was adjusted to achieve on the empty wagon with lubricated centre bowl.
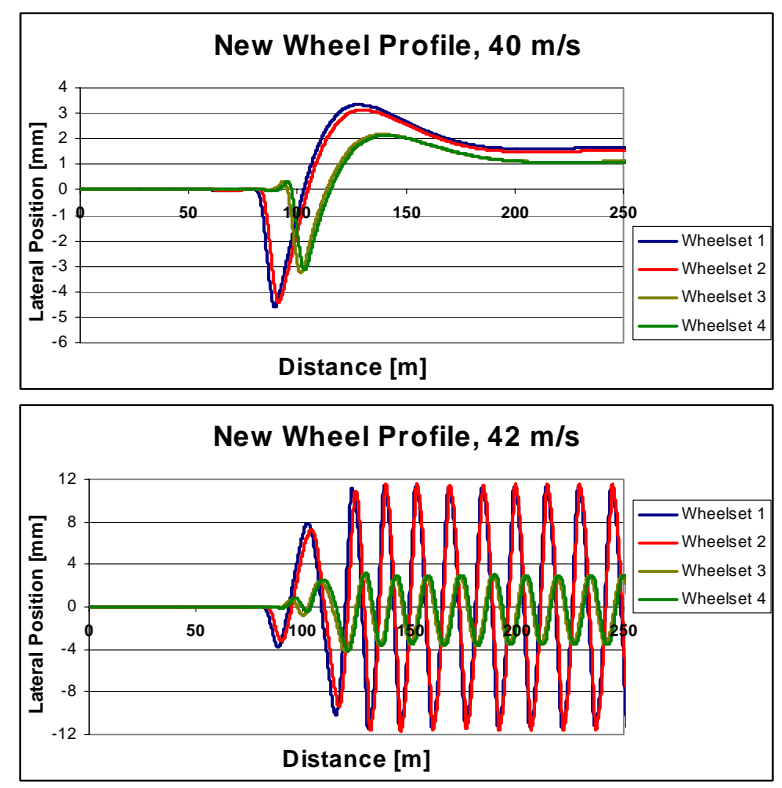

Figure 7 New wheel profile hunting using a smaller 1 $\mathrm{mm}$ excitation defect
This behavior of super critical stability is caused by the non-linear shape of the new wheel profile. In Figure 7 we see a smaller track defect has been used such that the wheelset lateral displacement is excited less then $5 \mathrm{~mm}$ from the neutral point. For this low conicity section of the wheel profile (Table 1) the critical hunting speed is $42 \mathrm{~m} / \mathrm{s}$ instead of $27 \mathrm{~m} / \mathrm{s}$. In operation it is unlikely that a wagon can travel great distances without some kind of track defect generating flange contact as a hunting initiator. Thus the lower hunting speed of $27 \mathrm{~m} / \mathrm{s}$ must be considered the vehicle's critical hunting speed for the default case.

\section{Friction Coefficient Sensitivities}

Further simulations were done varying the friction coefficient from the default case with changes at the centre bowl and also at the CCSB and Bearing adaptors. Using a lower friction level of 0.182 at the bearing adapter sideframe interface, the simulated wagon hunting speeds are given in Table 2. With a nominal 0.4 friction coefficient at the bearing adaptor, the hunting speed for the fully lubricated centre bearing $(0.1$ friction) and empty wagon was $48 \mathrm{~m} / \mathrm{s}$. If the constant contact side bearer friction is reduced to 0.3 the hunting speed reduces from $48 \mathrm{~m} / \mathrm{s}$ to $29 \mathrm{~m} / \mathrm{s}$. Thus it is evident the present model overstates the friction coefficient at the CCSB.

The wagon hunting speeds for the simulation defaults to the empty wagon hunting speed. The bogie design use of CCSB makes the hunting speed relatively insensitive to the centre bowl friction condition as very little of the bogie rotation friction is generated at the centre bowl interface. For the loaded wagon hunting speed is very sensitive to the centre bowl friction condition but that is of no bearing on the wagons minimum critical hunting speed which occurs with an empty wagon.

Table 2 New Wheel Profile Critical Hunting Speed

\begin{tabular}{|l|c|c|}
\hline \multicolumn{1}{|c|}{ Load } & $\begin{array}{c}\text { Centre } \\
\text { Bearing Case }\end{array}$ & $\begin{array}{c}\text { Critical Speed } \\
{[\mathrm{m} / \mathrm{s}]}\end{array}$ \\
\hline Empty & 0.1 & 27 \\
\hline Empty & 0.3 & 27 \\
\hline Empty & 0.5 & 29 \\
\hline Loaded & 0.1 & 35 \\
\hline Loaded & 0.3 & $>50$ \\
\hline
\end{tabular}

The simulation model is show to have a very high sensitivity to the bearing adaptor and CCSB friction coefficients with an increase in either friction coefficient increase the wagons critical hunting speed. The impact on hunting speed of the bearing adaptor's friction coefficient or the CCSB friction condition has not been fully investigated in this work. The vehicle model at present has several assumed friction coefficient values and the study presented here was performed after adjusting just one of these friction coefficients to obtain a hunting behavior considered consistent with the wagon type. Further work is required to investigate the effective rotational radius for friction at the bearing adaptor which is also given an arbitrary value in the model. 


\subsection{Worn Wheel Profile Performance}

The off centre wear of the worn wheel profiles generates simulation instability even in the absence of a track excitation defect. In Figure 8 the track defect is at $80-92 \mathrm{~m}$ but before that there is significant instability in the tracking of both bogies. Bogie 2 stabilizes after $150 \mathrm{~m}$ and bogie 1 after $200 \mathrm{~m}$. This is not real behavior in that a wagon would normally never sit in the neutral position with the four wheels centered on the track with zero angles of attack as is the start point for the simulation model. The wagon with these worn wheel profiles would normally sit skewed having angles of attack to the rail and tracking positions more likely reversed to those seen after 200 $\mathrm{m}$ in Figure 8 to generate the higher wear one the left wheels. It should be noted that the wagon simulation has a perfectly symmetric bogie suspension and a perfectly smooth track. The wheel profiles are from a wagon which is likely to have some non symmetric suspension characteristic such as misaligned CCSB.

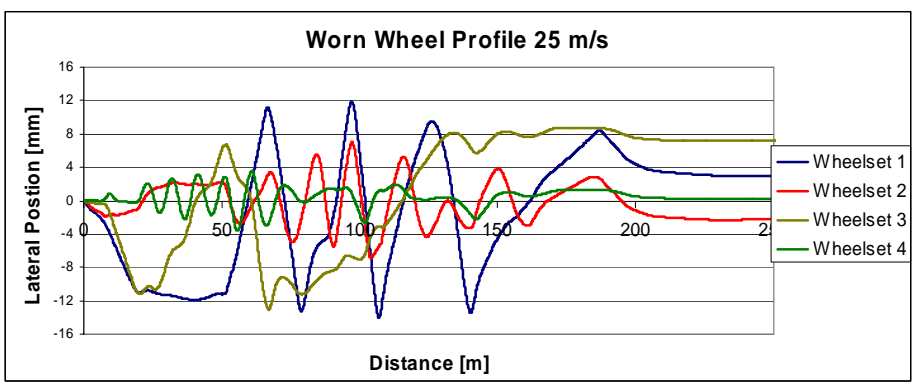

Figure 8 Simulated lateral instability due to uneven worn wheel profiles

The following simulations for hunting instability are consequentially excited by the initial tracking position of the worn wheel profiles more so than by the track misalignment. Figure 9 shows the dual bogie hunting mode of the worn wheel profiles. The leading wheels of the bogie hunt with a wavelength of approximately $26-30 \mathrm{~m}$ whilst the trailing wheels hunt at a wavelength of average 12-16 m. Because of the differences in the wheel profiles of the different wheelsets we can see differing frequency responses in the front and rear wheelsets of each bogie. The critical hunting speed for the empty VSA wagon with worn wheel profiles was identified as $25 \%$ higher than the new wheel profile at $35 \mathrm{~m} / \mathrm{s}$.

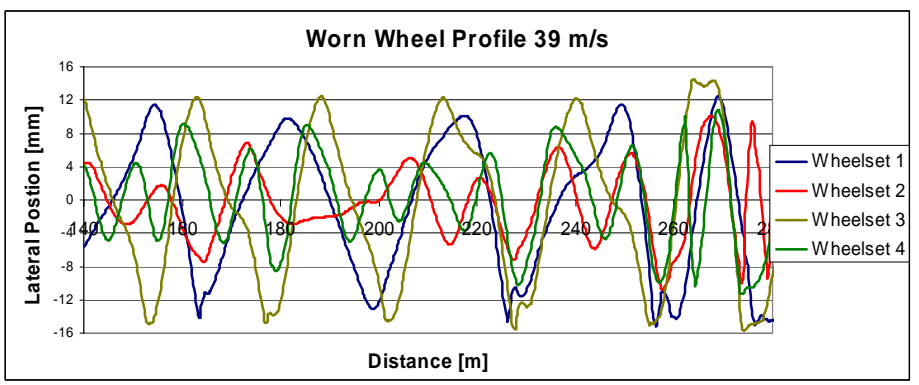

Figure 9 Worn Profile wheels in a dual bogie hunting mode

\subsection{Leading and Trailing Wheel Performance}

To appreciate this behavior of the uni-directional wheel profiles properly we need to review their behavior individually. This lets us draw better comparison to the Klingel wavelengths given in Table 1. The leading wheel profile with both flange wear and significant tread hollowing is highly non-linear, the Klingel wavelength varying from $8-21 \mathrm{~m}$. Non-linear conicity leads to essentially chaotic behavior in wheel tracking. Figure 10 and Figure 11 show how the leading wheel profile hunts in a single bogie mode at $21 \mathrm{~m} / \mathrm{s}$, is stable at $23 \mathrm{~m} / \mathrm{s}$, has an on / off double bogie mode at $35 \mathrm{~m} / \mathrm{s}$, and is stable again at $37 \mathrm{~m} / \mathrm{s}$.
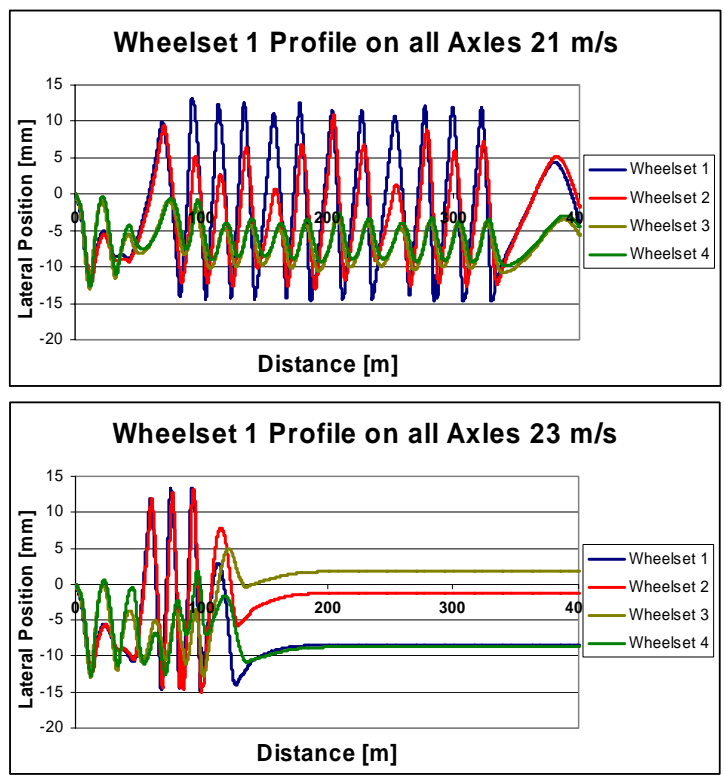

Figure 10 Leading Wheel Profile on All Wheels at 21 and $23 \mathrm{~m} / \mathrm{s}$
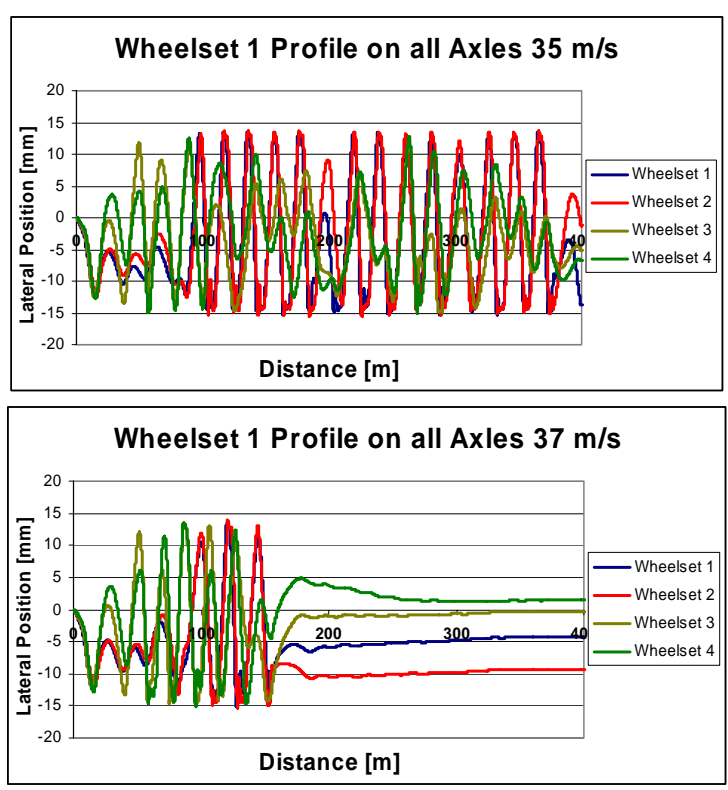

Figure 11 Leading Wheel Profile on All Wheels at 35 and $37 \mathrm{~m} / \mathrm{s}$

The hunting wavelength of the leading bogie seen in Figure 10 and Figure 11 is an average of $22-23 \mathrm{~m}$. This is 
roughly double the bogie centre spacing. This wavelength is a close match to neutral zone conicity Klingel wavelength of 21 $\mathrm{m}$ and is no match to the total conicity Klingel wavelength of $8.2 \mathrm{~m}$. At $21 \mathrm{~m} / \mathrm{s}$ (Figure 10) the hunting mode is for the lead bogie only whilst at $35 \mathrm{~m} / \mathrm{s}$ (Figure 11) the hunting mode is in phase hunting of both bogies.

The trailing wheel profile has tread hollowing but essentially no flange wear. The contact profile for the trailing wheel is a good approximation of linear conicity of 0.174 radians for wheelset 2 with a small variation to 0.137 . Wheelset four has a more linear profile with a slightly high conicity. Such a high wheel conicity gives a low hunting speed and a short wavelength for hunting oscillations. Figure 12 shows critical hunting for the trailing wheel profile is at $22 \mathrm{~m} / \mathrm{s}$ and the wavelength of hunting as $12.3 \mathrm{~m}$ which is significantly longer than the Klingel wavelength of $7.5-8.4 \mathrm{~m}$.
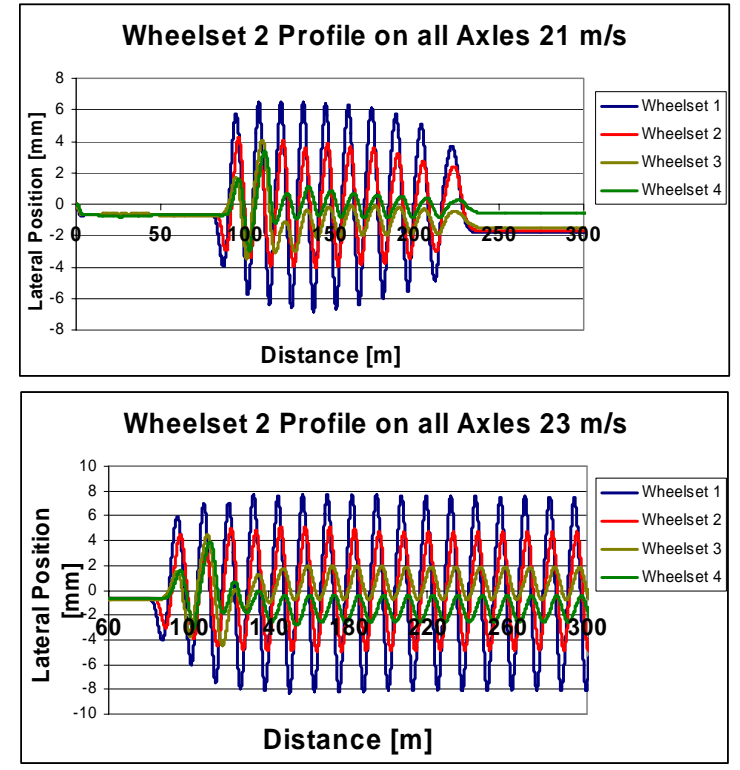

Figure 12 Trailing Wheel Profile on All Wheels at 21 and $23 \mathrm{~m} / \mathrm{s}$

In Figure 12 the hunting mode is single bogie only. Above a speed of $29 \mathrm{~m} / \mathrm{s}$ an in phase dual bogie mode takes over from the single bogie mode due to increase amplitude in the rear bogie responce.

\subsection{Wheel Wear performance}

Curving performance was conducted on eleven track sections representing the actual vehicle operation in the Goonyella coal system. Track curves are $29 \%$ of the Goonyella coal system. Results given here are based on the initial vehicle model for the VSA wagon featuring 0.5 friction coefficient at the CCSB and 0.4 friction coefficient at the bearing adaptors. The summarised wear results are given in As seen in Error! Not a valid bookmark self-reference. the worn wheel profiles have lower wear energy than the new wheel profile. The better wear performance of the worn wheel profiles is due to the higher effective conicity at flange travel limits of these worn profiles. The worn profiles have 3-4 $\mathrm{mm}$ difference in the rolling radius of the two wheels when flanging while the new wheel profile has less than $2 \mathrm{~mm}$ difference in rolling radius, (see Figure 2, Figure 3 and Figure 4). Table 2 also shows the Goonyella Coal operations wheel wear sensitivity to center bearing friction condition.

Table 3. Wear results are dominated by the loaded wagon performance where wear rates are 2-10 times higher than the empty wagon wear results.

As seen in Error! Not a valid bookmark self-reference. the worn wheel profiles have lower wear energy than the new wheel profile. The better wear performance of the worn wheel profiles is due to the higher effective conicity at flange travel limits of these worn profiles. The worn profiles have 3-4 $\mathrm{mm}$ difference in the rolling radius of the two wheels when flanging while the new wheel profile has less than $2 \mathrm{~mm}$ difference in rolling radius, (see Figure 2, Figure 3 and Figure 4). Error! Not a valid bookmark self-reference. also shows the Goonyella Coal operations wheel wear sensitivity to center bearing friction condition.

Table 3 Wear Results for New and Worn Wheel Profiles

\begin{tabular}{|c|c|c|}
\hline $\begin{array}{c}\text { Center Bearing } \\
\text { Friction }\end{array}$ & $\begin{array}{c}\text { New Wheel } \\
{[\mathrm{MJ} / \text { wagon }]}\end{array}$ & $\begin{array}{c}\text { Worn Wheel } \\
{[\mathrm{MJ} / \text { wagon }]}\end{array}$ \\
\hline 0.10 & 84.8 & 63.5 \\
\hline 0.30 & 96.1 & 64.2 \\
\hline 0.50 & 104.8 & 82.1 \\
\hline 0.99 & 127.7 & 86.5 \\
\hline
\end{tabular}

\section{DISCUSSION}

\subsection{Worn Wheel Profiles}

The wheel profiles from QR National's VSA coal wagon operations in the Goonyella system of Central Queensland show a distinct pattern of flanging wear occurring only on lead wheels of each three piece bogie. This is because the majority of wheel wear occurs in medium radius curves. Medium curves are being defined in this study as curve radii where only two wheels flange, the first and third wheelset of the wagon.

As a result the wagons which operate only in one direction develop two distinct wheel profile patterns, one for the leading wheels that exhibits tread and flange wear and another for the trailing wheel that exhibits tread wear only. The particular wheel profiles used also display an uneven wear pattern on the leading wheel with far greater wear on the left hand wheel. This wear pattern is likely due to some unevenness in the setup of the two CCSB or between the left and right friction wedges. The alternative is a higher proportion of right hand curves for the loaded wagon.

The tight tolerances of normal travel CCSB make this the most likely source of bogie faults. In this case a tighter fit to the left hand CCSB is likely to generate great bogie warp and angle of attack in right hand curves, increasing the wheel wear on the left hand wheel in both empty and loaded operation. 


\subsection{Hunting Behaviour}

The new wheel profile of the VSA wagon has non-linear conicity that permits the wagon to obtain a super critical speed should the track contain no significant misalignments. If the lateral displacement of the wheelset can be limited to within $5 \mathrm{~mm}$ of centre then the critical hunting speed of the wagon is $175 \%$ of the wagons true critical hunting speed. Depending on the wavelength, the defect required to excite the new wheel laterally beyond $6 \mathrm{~mm}$ to a region of high effective wheel conicity may be as small as $1.5 \mathrm{~mm}$ as used in this study.

The worn wheel profiles of the VSA wagon behave in a highly non-linear manner during hunting excitation. This behavior is generated by the leading wheel profile (Figure 3) and by the differences between the leading and trailing wheel profiles (Figure 4) within each bogie.

Individually the leading wheel with its non-linear shaped profile has chaotic behavior and a preferred wavelength of 22$23 \mathrm{~m}$, the onset of chaotic instability occurring at $21 \mathrm{~m} / \mathrm{s}$. The trailing wheel with its near linear profile and high conicity similarly goes unstable at $22 \mathrm{~m} / \mathrm{s}$ but displays a classic sinusoidal hunting motion of $12.3 \mathrm{~m}$ in wavelength. Both profiles are significantly less stable than the new wheel profiles' critical hunting speed of $27 \mathrm{~m} / \mathrm{s}$ with a $15 \mathrm{~m}$ wavelength. The critical hunting speed for an individual wheel profile appears more closely related to the total effective rolling radius change in the contact profile than either the total conicity or neutral zone conicity. The wavelength of the hunting oscillation is a combination of the neutral zone and to a seemingly small extent the total conicity with simulation results being $15-50 \%$ longer then the Klingel equation for free moving wheelsets.

The hunting behavior of the combined worn wheel profiles of trailing and leading wheels of a bogie are considerably better than the individual wheel profiles by themselves. The highly linear conicity of the trailing wheel steers the bogie whilst the non-linear profile of the leading wheel damps out the hunting behavior of the trailing wheel. In the combined bogie we see the trailing wheel hunting wavelength is altered from a consistent $12.3 \mathrm{~m}$ to between $12-16 \mathrm{~m}$ and the chaotic leading wheels behavior is also altered slightly to be $26-30 \mathrm{~m}$ and become regularly double the trailing wheel frequency.

The competing hunting frequencies within the same bogie have meant that the hunting behavior is heavily damped by the competing bogie warp and rotation demands. The increase to the wavelength of hunting for both leading and trailing wheels reflects this damping effect. The result is a greatly inflated critical hunting speed for the worn wheelsets which has gone from an expected $21 \mathrm{~m} / \mathrm{s}$ or $80 \%$ of the new wheel hunting speed to $35 \mathrm{~m} / \mathrm{s}$ or $125 \%$ of the new wheel hunting speed.

There can be some advantage then taken with such unidirectional worn wheel profiles, whereas most wagons can be expected to have lowered critical hunting speeds from wheel wear, hunting risk will diminish with wear. This it must be noted may not hold true for any wagon that does develop a hunting problem as the wheel profile wear patterns would then alter.

\subsection{Uni-directional Profile Disadvantages}

The research presented in this paper has not investigated any of the disadvantages of uni-directional wheel profile wear. Several disadvantages are readily identifiable in operating rollingstock in one direction. Firstly the rapid flange wear on leading wheels reduces the wear life cycles compared to sharing such wear over all wheels. The mismatch in profile shapes for leading and trailing wheels could increase impact loads in special track work. These are significant disadvantages and thus any move to uni-directional train operations must be justified by the train operational benefits.

\section{CONCLUSION}

Three piece bogies operating in one direction of travel in network with majority wheel wear from medium radius curves develop differing wheel profiles for leading and trailing wheelsets. The leading wheels develop non-linear conicity through a combination of flange and tread wear. The trailing wheels develop linear high conicity profiles through tread wear only.

The worn wheel profiles by themselves for both leading wheel and trailing wheel have been found to have critical hunting speeds $80 \%$ of the new wheel profile critical speed. In combination as found in a wagon operating in one direction, the leading and trailing wheel profiles produce a critical hunting speed $125 \%$ of the new wheel profiles critical hunting speed. The damping of the lateral instability dynamics is generated by the mismatch in the hunting motion dynamics of the two wheelsets within the same bogie, the bogie hunting motion combining the leading and trailing wheel motions.

Hence in uni-directional train operations it is likely that the lateral instability critical speed will increase with wheel wear at the same time as curving performance improves with wheel wear.

Bogie hunting behavior for a three piece bogie has been shown in simulation to be very sensitive to the friction conditions as modeled at the bearing adaptors and the CCSB wear pads. Centre bearing rotation friction is shown to be of small consequence when as for the VSA wagon the majority of the wagon body's tare weight is taken up the in CCSB preloads leaving little force at the center bowl.

\section{ACKNOWLEDGMENTS}

Support and funding for this research has been provided by the Cooperative Research Centre for Railway Engineering and Technologies (Rail CRC), Australia, the research being part of an investigation of bogie rotation friction management. In particular the Rail CRC industry partner QR National are thanked for their support in the provision of case study data for the VSA wagon and its operation in Central Queensland coal fields. 
This research has been conducted utilizing the software VAMPIRE ${ }^{\circledR}$ and the support of AEA Technology Rail.

\section{REFERENCES}

[1] Simson S. A., Pearce M., 2004, "Longitudinal Impact Forces at 3 Piece Bogie Center Bearings" ASME/IEEE Joint Rail Conference, 2005, American Society of Mechanical Engineers, Rail Transportation Division (Publication) RTD, v 29, p 45-50.

[2] Wu, H., 2002, "Effect of Center Plate Lubrication on Vehicle Curving and Lateral Stability", Research Report R-959, Association of American Railroads / Transport Technology Center, Inc, Pueblo Colorado.
[3] Katta, R. R., Thomas C. F., 2004, “A Dynamic Stiffness and Damping Model for Rail Car Center Plate Polymer Liners" Proc. 2004 ASME/IEEE Joint Rail Conference, ASME, Baltimore Maryland, pp. 63-73

[4] Simson S. A., Pearce M., 2006, "Centre Bearing Rotation Forces During Curve Transitions", Proc. Conference on Railway Engineering 2006, April 30 - May 3, RTSA, Melbourne, Preprint

[5] Wickens A. H., Fundamentals of rail vehicle dynamics: Guidance and stability. Lisse: Swets \& Zeitlinger, 2003 